\section{Resistance and Stress Finite Element Analysis of Different Types of Fixation for Mandibular Orthognathic Surgery}

Diego José Stringhini' ${ }^{1}$ Ricardo Sommerfeld ${ }^{1}$, Lucas Caetano Uetanabaro², Denise Piotto Leonardi², Melissa Rodrigues Araújoº ${ }^{2}$ Nelson Luís Barbosa Rebellato ${ }^{1}$, Delson João da Costa', Rafaela Scariot ${ }^{2}$

\author{
'Graduate Program in Dentistry, \\ UFPR - Universidade Federal do \\ Paraná, Curitiba, PR, Brazil \\ ${ }^{2}$ Graduate Program in Dentistry, \\ UP - Universidade Positivo, \\ Curitiba, PR, Brazil
}

Correspondence: Dra. Rafaela Scariot, Rua Deputado Heitor Alencar Furtado 3180, 13W, 81200-110 Curitiba, PR, Brasil. Tel: +55-41-3285-9394. e-mail: rafaela_scariot@yahoo.com.br

\begin{abstract}
The aim of this study was to evaluate the stress and dislodgement resistance by finite element analysis of different types of fixation in mandibular orthognathic surgery. A 3D solid finite element model of a hemi-mandible was obtained. A bilateral sagittal split osteotomy was simulated and the distal segment was advanced $5 \mathrm{~mm}$ forward. After the adjustment and superimposing of segments, 9 different types of osteosynthesis with 2.0 miniplates and screws were simulated: $A$, one 4-hole conventional straight miniplate; $B$, one 4-hole locking straight miniplate; $C$, one 4-hole conventional miniplate and one bicortical screw; $D$, one 4-hole locking miniplate and 1 bicortical screws; $E_{\text {, one }}$ 6-hole conventional straight miniplate; $F$, one 6-hole locking miniplate; $G$, two 4-hole conventional straight miniplates; $\mathrm{H}$, two 4-hole locking straight miniplates; and I, 3 bicortical screws in an inverted-L pattern. In each model, forces simulating the masticatory muscles were applied. The values of stress in the plates and screws were checked. The dislodgement resistance was checked at the proximal segment since the distal segment was stable because of the screen at the occlusal tooth. The regions with the lowest and highest displacement were measured. The offset between the osteotomized segments was verified by millimeter intervals. Inverted- $L$ with bicortical screws was the model that had the lowest dislodgment and the model with the lowest tension was the one with two conventional plates. The results suggest that the tension was better distributed in the locking miniplates, but the locking screws presented higher concentration of tension.
\end{abstract}

Key Words: orthognathic surgery, mandibular, fixation, resistance, stress.

\section{Introduction}

The bilateral sagittal split osteotomy of the rami (BSSO) is recognized as a standard procedure for treatment of certain mandibular discrepancies. The bone stabilization progressed from osteosynthesis by steel wire with maxillomandibular intermaxillary block (MMI) to the rigid internal fixation with titanium miniplates and screws. The problems with MMI are well known and include involvement of the upper airways, nutritional problems and related weight loss, temporomandibular joint wear and ankylosis and lack of cooperation from the patients (1-3). The stable internal fixation is the standard procedure used to stabilize the BSSO in oral and maxillofacial surgery (3). Different methods of internal fixation have been used to allow quick mobility and the return to function after BSSO. However, some disadvantages related to methods of rigid fixation should be remembered, like displacement of the condyle, irreversible nerve injuries related to compression caused by screws or miniplates, difficulty in cases of reintervention and occlusal changes (4).

Most current procedures use titanium as fixing material due to its stiffness, strength and biocompatibility (5). These properties provide stabilization of the osteotomized segment with minimum movement. Consequently, the fixation procedures with this type of material improved radically the outcomes and increased bone union rates (6).

The stable internal fixation uses titanium miniplates and various types of screws. Numerous variations in the use of plates and screws may be obtained depending on the operator's preference: bicortical screws alone, miniplates with monocortical screws or hybrid technique, when miniplates and bicortical screws are combined with bicortical screws (7).

In order to obtain the appropriate anchorage, may be used miniplates and $1.5 \mathrm{~mm}, 2.0 \mathrm{~mm}$ and $2.3 \mathrm{~mm}$ screws, both of conventional or locking system. Numerous variations can be made: 4-hole or 6-hole miniplates, two 4-hole or 6-hole miniplates, one dual Y miniplate and other combinations.

The locking miniplates systems are those in which the screw head sets itself into the miniplate. Thus, they tend to minimize the movement of the osteotomized segments, since with these miniplates there is a decrease of traction in the bone segments. This system prevents excessive compression of the miniplate and screw against the cortical bone, which can lead to bone resorption (8). 
In vitro studies and clinical tests have shown that the 2.0-mm miniplate locking systems have greater strength than the conventional ones $(8,9-11)$. The use of this type of fixation has been extensively documented in surgeries to treat facial fractures, but little has been explored in orthognathic surgery $(9,10)$.

Some studies used biomechanical models for simulations in vitro, while other studies used analysis by three-dimensional finite element to compare different types of fixation (12-16). The major difficulty in studies involving biomechanical testing is how to properly simulate the action of the mastication muscles. The vast majority of studies, both in vitro and by finite element analysis, reported that the fixation technique using 3 bicortical screws in inverted- $L$ arrangement is the one that provides greatest stability. However, there is still room for discussion about which technique is more effective and causes fewer complications, especially when major advances are required or in cases of mandibular asymmetry, given the evolution of the materials used for this purpose.

The purpose of this study was to verify the stress and dislodgement by finite element analysis of nine different types of rigid internal fixation, and to compare the stability and stress of the conventional miniplate and screws with the locking system. The main hypothesis of this study is that the fixation systems with bicortical screws have lower resistance to displacement when compared to monocortical screws. Furthermore, it is expected that the plates of the locking system are superior to conventional plates as regards the resistance to displacement and stress.

\section{Material and Methods}

A three-dimensional solid from computed tomography images of a mandible was downloaded from www.osirixviewer.com/datasets for simulation by finite element analysis. Files containing the 3D images of titanium miniplates and screws were provided by Neortho Enterprises (Curitiba, PR, Brazil). This study used the following images: 4-hole conventional $2.0-\mathrm{mm}$ miniplate, 4-hole locking 2.0-mm miniplate, 6-hole conventional 2.0- $\mathrm{mm}$ miniplate, 6-hole locking 2.0- $\mathrm{mm}$ miniplate, $2.0-\mathrm{mm}$ conventional screw $6 \mathrm{~mm}$ long, 2.0-mm locking screw $6 \mathrm{~mm}$ long and 2.0-mm conventional screw $15 \mathrm{~mm}$ long.

After obtaining the three-dimensional model, the files were split into thousands of triangles and exported to Solidworks 2012 software (Dassault Systemes, Solidworks Corp., Vélizy, France), in order to remove the interference among the aforementioned triangles and make them compatible with the readings at the Ansys Workbench 14.0 (NASDAQ:ANSS) software used in this simulation (Fig. 1).

A sagittal bilateral split osteotomy at the distal segment with a $5 \mathrm{~mm}$ forward advance was simulated in the program.
From this new osteotomized model, 9 different types of fixations were simulated. In Group A, two conventional $2.0 \mathrm{~mm}$ diameter $/ 6 \mathrm{~mm}$ long monocortical screws were installed in each bone segment using a conventional miniplate with space (Fig. 2A). In Group B, two locking $2.0 \mathrm{~mm}$ diameter $/ 6 \mathrm{~mm}$ long monocortical screws were installed in each bone segment using a locking miniplate with space (Fig. 2B). In Group C, two conventional $2.0 \mathrm{~mm}$ diameter/6 $\mathrm{mm}$ long monocortical screws were installed in each bone segment using one conventional miniplate with space and one conventional $2.0 \mathrm{~mm}$ diameter and 15 $\mathrm{mm}$ long screw reaching both cone cortices $3 \mathrm{~mm}$ distal from second molar below the superior alveolar border (Fig. 2C). In Group D, two locking $2.0 \mathrm{~mm}$ diameter $/ 6 \mathrm{~mm}$ long monocortical screws were installed in each bone segment using a locking miniplate with space and one conventional $2.0 \mathrm{~mm}$ diameter $/ 15 \mathrm{~mm}$ long screw reaching both bone cortices $3 \mathrm{~mm}$ distal from the second molar below superior alveolar border (Fig. 2D). In Group E, three conventional $2.0 \mathrm{~mm}$ diameter $/ 6 \mathrm{~mm}$ long monocortical screws were installed in each bone segment using a conventional miniplate with space (Fig. 2E). In Group F, three locking 2.0 $\mathrm{mm}$ diameter $/ 6 \mathrm{~mm}$ long monocortical screws were installed in each bone segment using a locking miniplate with space (Fig. 2F). In Group G, two conventional 4-hole miniplates with space with two conventional $2.0 \mathrm{~mm}$ diameter $/ 6 \mathrm{~mm}$ long monocortical screws per plate were installed in each bone segment. One miniplate was installed close to the superior border of the bone segment and the other above the basal line (Fig. 2G). In Group H, two 4-hole locking miniplates with space with two locking $2.0 \mathrm{~mm}$ diameter/6 $\mathrm{mm}$ long monocortical screws per plate were used in each bone segment. One miniplate was installed close to the superior border of the bone segment and the other above the basal line (Fig. 2H). In Group I, three bicortical screws

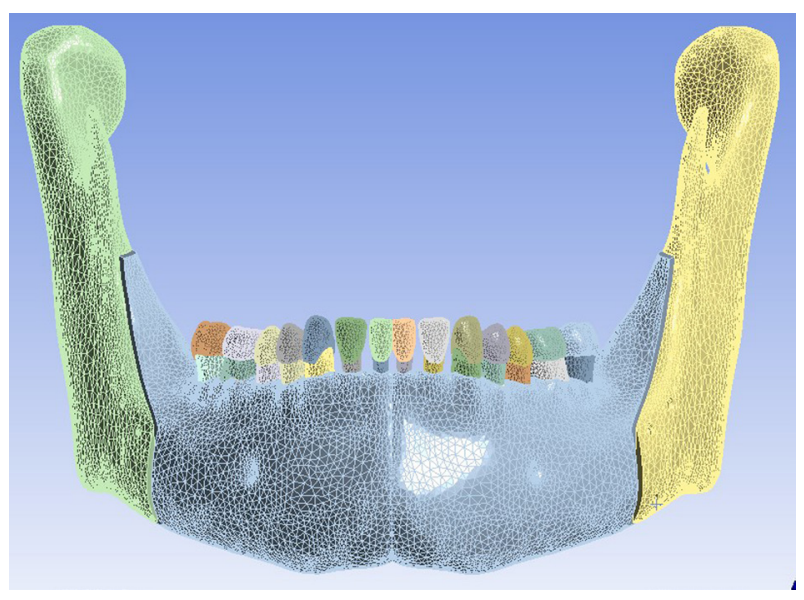

Figure 1. Solid used in the simulation, showing the bilateral sagital split osteotomy with $5 \mathrm{~mm}$ advance and all elements. 
were installed in a inverted-L position (Fig. 1I).

The structures were divided into: enamel, dentin, pulp, periodontal ligament, trabecular bone and cortical bone, considering a homogeneous, isotropic and linear elastic behavior. Forces were applied in the region of the insertion of the temporal muscle (lateral margin of the coronoid process of the mandible) $-235 \mathrm{~N}$, medial pterygoid muscle (pterygoid tuberosity) $-145 \mathrm{~N}$ and the masseter muscle
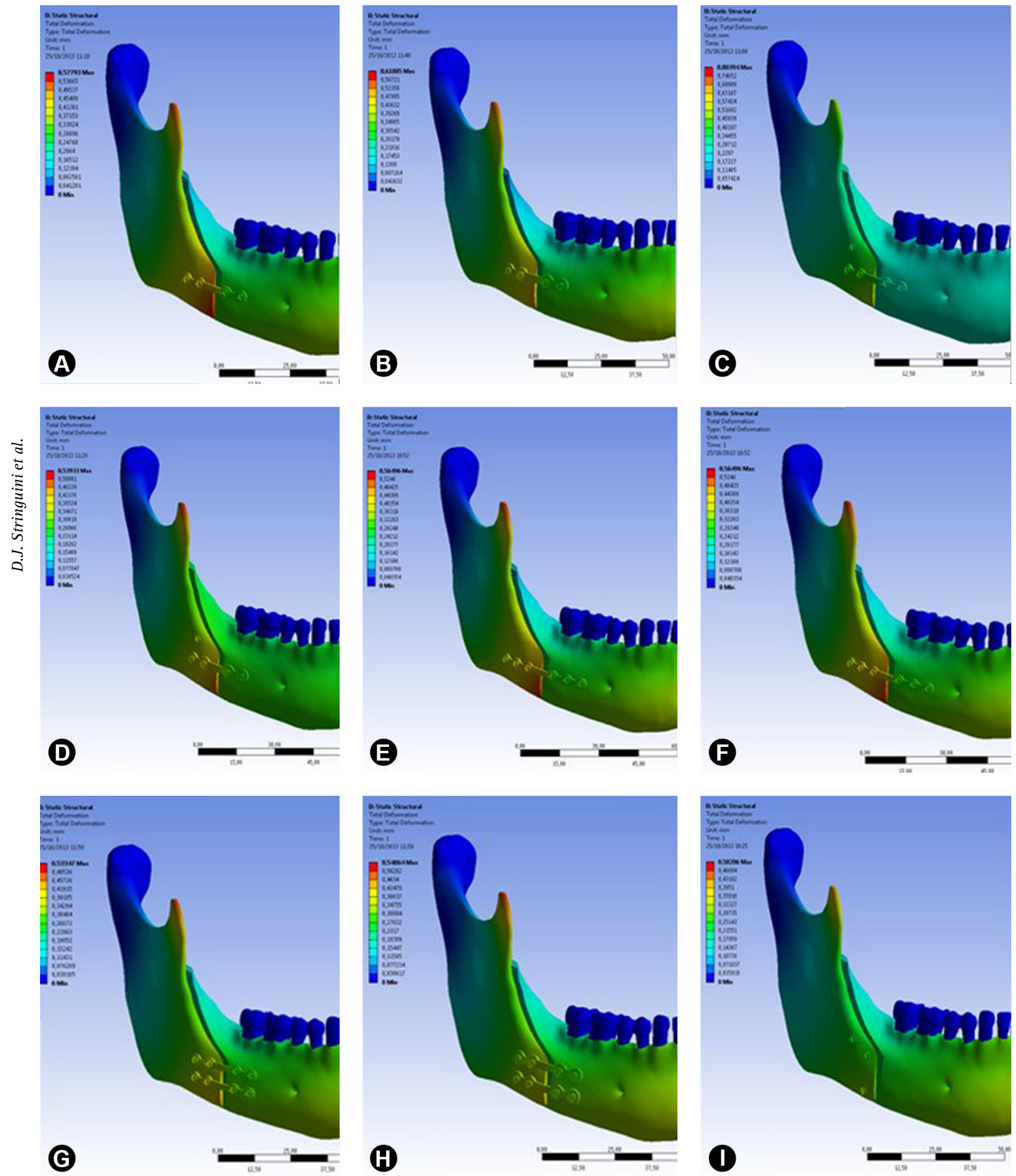

Figure 2. Simulation of bone segment displacement with the 9 different fixation methods. 
(lateral side of the mandible) - $151 \mathrm{~N}$, which are involved in the lifting of the mandible during the masticatory act. The bulkhead was applied on the occlusal surfaces of the teeth (15) (Fig. 3).

After this simulation the stress of the plates was evaluated in $\mathrm{MPa}$ and the displacement resistance was measured in millimeters. The dislodgement resistance was checked at the proximal segment, since the distal segment was stable because of the screen at the occlusal tooth, the region with the lowest displacement and the region with the highest displacement was measured. The longer and higher the values, the greater the stress and displacement of the miniplates. The screws were evaluated separately and the stress was evaluated only once to verify the displacement. In the stress simulations, green color demonstrates less stress and red color is related to higher stress values.

\section{Results}

All the different models with different configurations of fixation were subjected to the same force intensity, each one evaluated separately regarding the displacement between the bone segments and the stress on the miniplates and screws. In the stress simulations green color demonstrates less stress and red color is related with higher stress values, but the colors between the simulations could not be compared because each one has a different interval of values. The stress results, even in the miniplates and screws, are presented in Table 1.

As expected, the inverted-L screws were the configuration that demonstrated the lowest displacement, but it did not present the lowest stress on the screws. Two conventional miniplates was the simulation with the lowest stress on the screws.

Comparing the fixation methods that use conventional miniplates with the locking miniplates, were obtained the following results:

Table 1. Values of miniplate tension, bone segment displacements and screw tension of each fixation method

\begin{tabular}{lccc}
\hline $\begin{array}{l}\text { Type of } \\
\text { fixation }\end{array}$ & $\begin{array}{c}\text { Miniplate } \\
\text { tension }(\mathrm{MPa})\end{array}$ & $\begin{array}{c}\text { Displacement } \\
(\mathrm{mm})\end{array}$ & $\begin{array}{c}\text { Screw tension } \\
(\mathrm{Mpa})\end{array}$ \\
\hline $\mathrm{A}$ & 17.395 & $0.53-0.49$ & 22.352 \\
$\mathrm{~B}$ & 34.208 & $0.52-0.43$ & 360.25 \\
$\mathrm{C}$ & 13.381 & $0.38-0.50$ & 79.679 \\
$\mathrm{D}$ & 27.481 & $0.34-0.45$ & 132.33 \\
$\mathrm{E}$ & 37.783 & $0.56-0.52$ & 59.961 \\
$\mathrm{~F}$ & 40.214 & $0.55-0.51$ & 74.048 \\
$\mathrm{G}$ & 19.09 & $0.30-0.34$ & 113.2 \\
$\mathrm{H}$ & 20.643 & $0.30-0.34$ & 96.21 \\
$\mathrm{I}$ & 22.562 & $0.21-0.28$ & 238.06 \\
\hline
\end{tabular}

A: 4-hole conventional miniplate; B: 4-hole locking miniplate; C: 4-hole conventional miniplate + bicortical screw; D: 4-hole locking miniplate + bicortical screw; E: 6-hole conventional miniplate; F: 6-hole locking miniplate; G: Two 4-hole miniplates; H: Two 4-hole locking miniplates; I: 3 bicortical screws in inverted-L pattern.

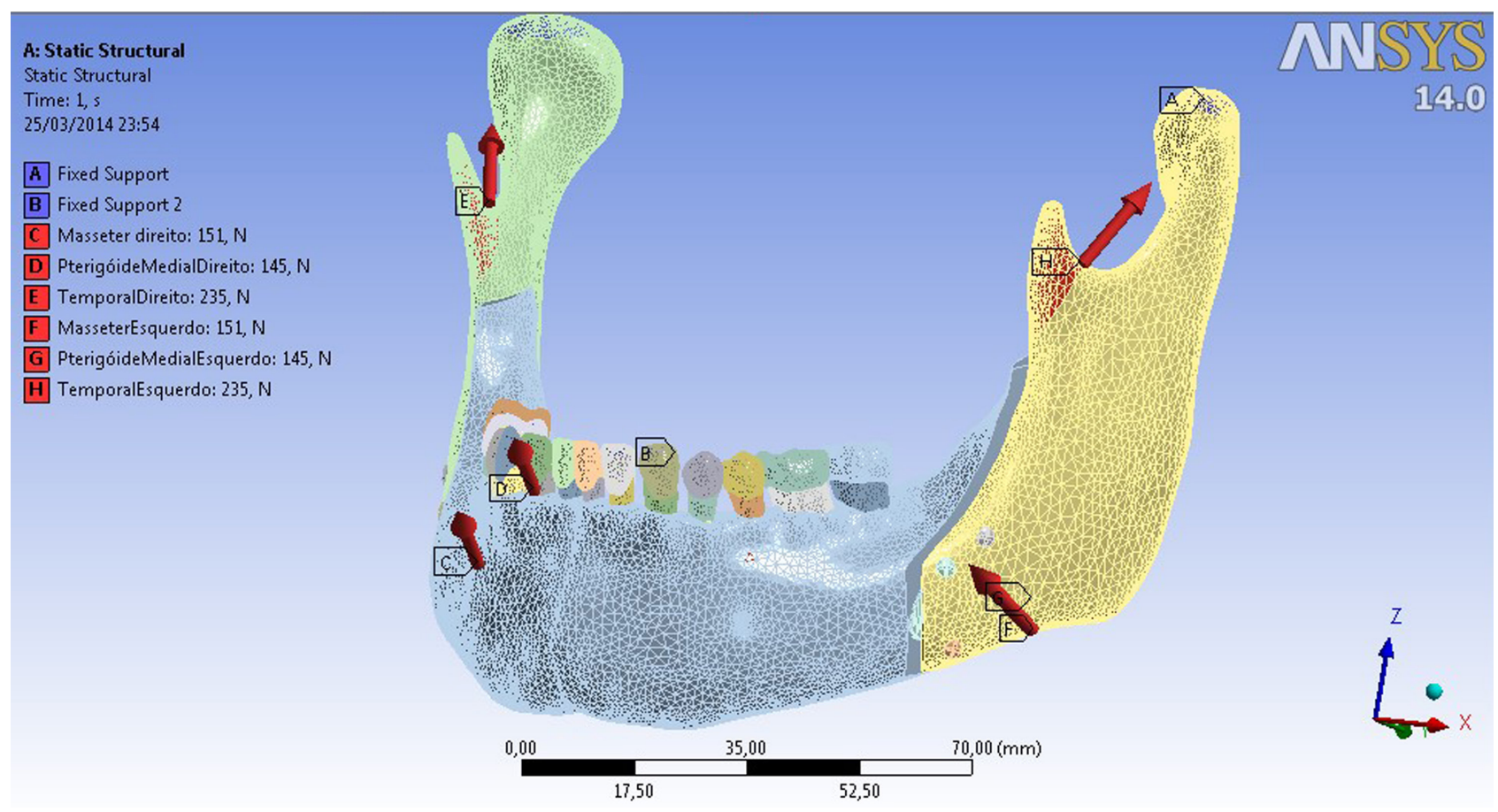

Figure 3. Simulation of forces promoted by the masticatory muscles. 
Conventional 4-hole miniplate $x$ locking 4-hole miniplate: The locking 4-hole miniplate yielded higher tension (Fig. 4) than the conventional miniplate and higher displacement resistance values of the bone segments (Fig. 5). Similar tension values were verified on the locking and conventional screws (Fig. 6).
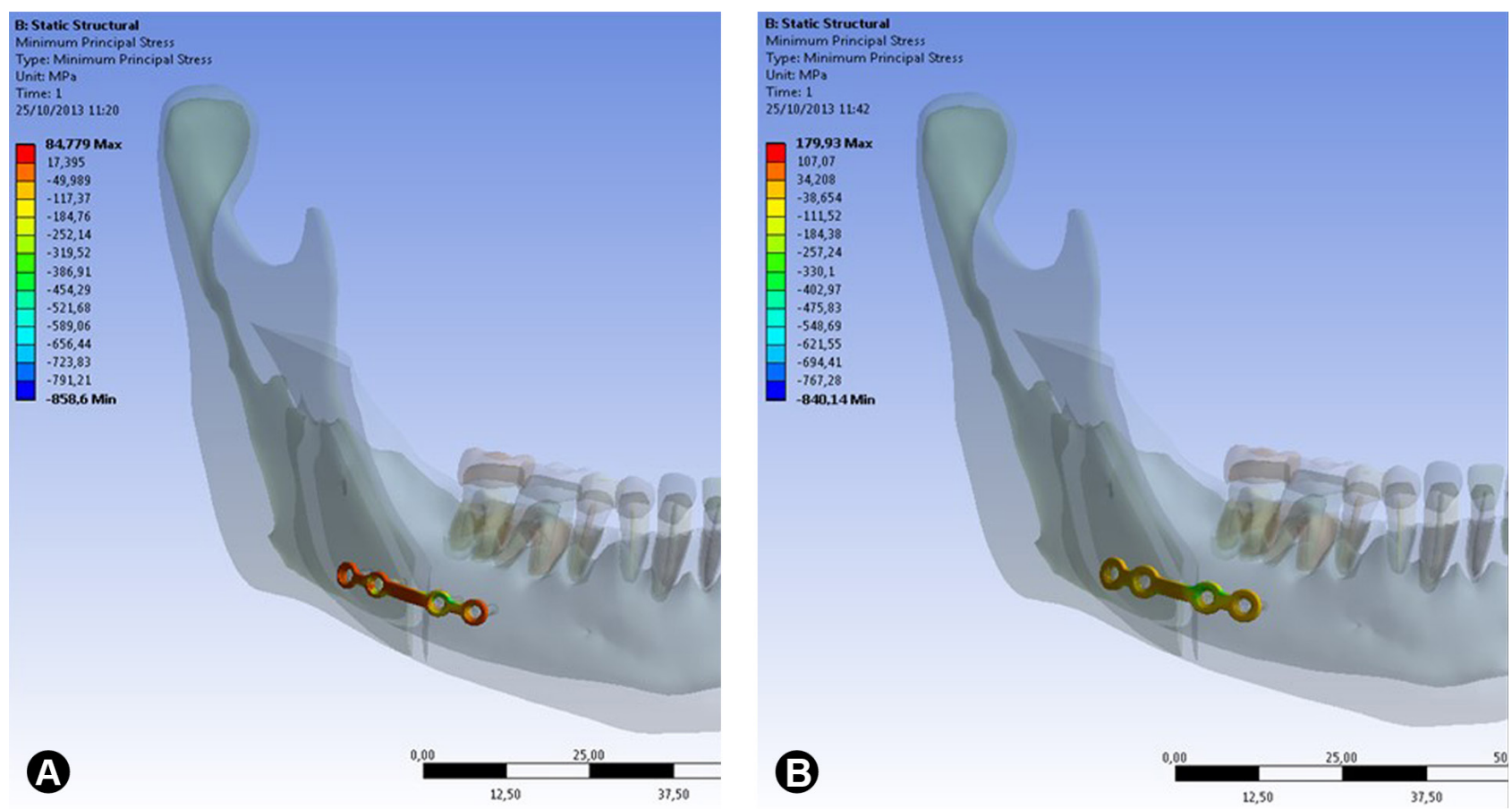

Figure 4. Images illustrating tension in the miniplates. A: conventional miniplate. B: locking miniplates. The red regions demonstrate higher stress values, but the two simulations cannot be compared because of the different stress intervals used to establish the colors.
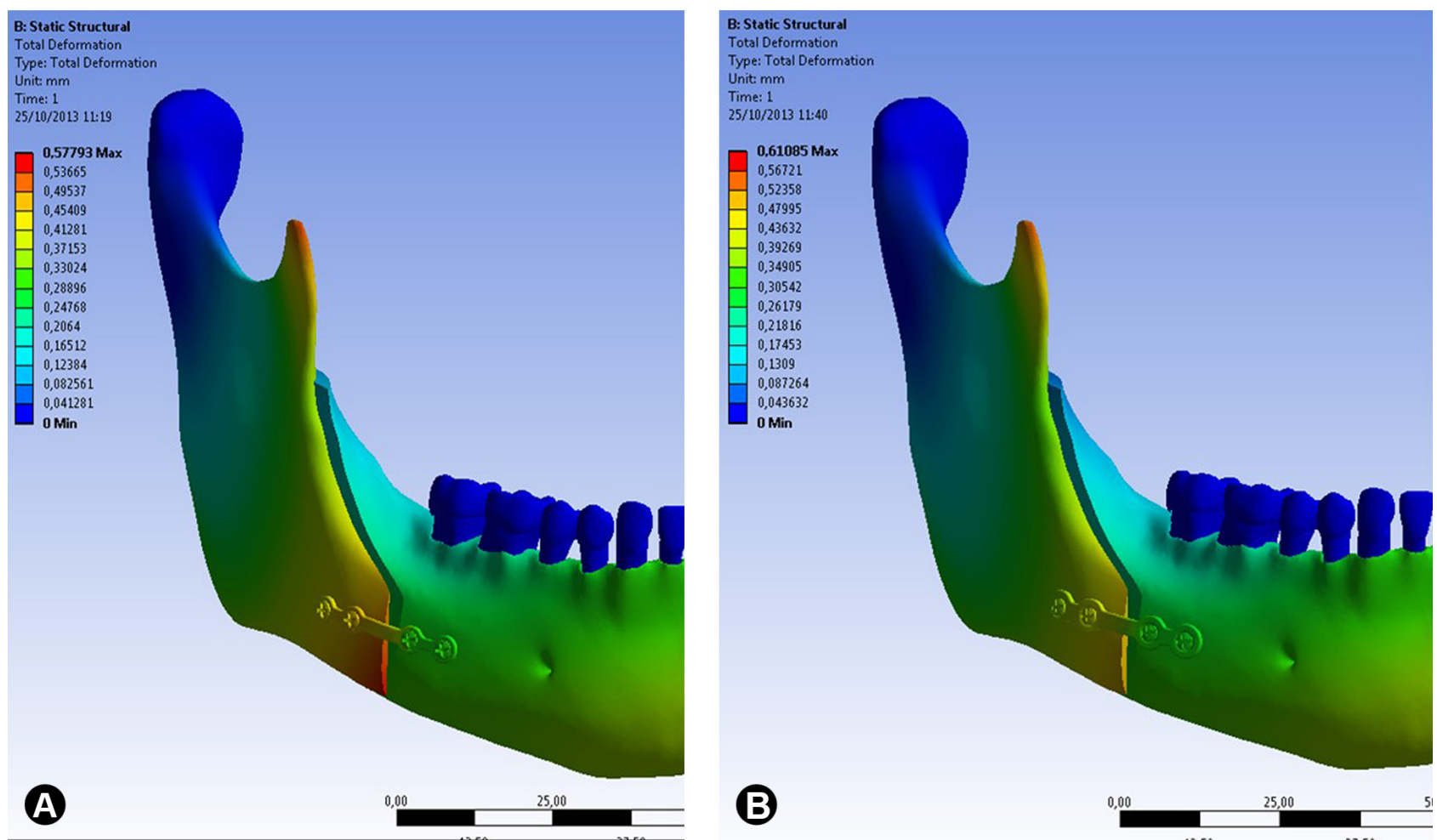

Figure 5. Images illustrating displacement of the miniplates. A: conventional 4-hole miniplate ( 0.53 to $0.49 \mathrm{~mm}$ ). B: locking 4-hole miniplate (0.52 to $0.43 \mathrm{~mm}$ ). 
Conventional 4-hole miniplate + bicortical screw $x$ locking 4-hole miniplate + bicortical screw: The locking 4-hole miniplate + bicortical screw yielded higher tension on the plate than the conventional one. The bone displacement resistance was higher with the locking 4-hole miniplate. The tension at the screws in this specific simulation was higher on the locking screws.

Conventional 6-hole miniplates $x$ locking 6-hole miniplates: The tension in the 6-hole locking miniplates was higher than on the conventional miniplates. The displacement resistance was slightly lower on the conventional miniplate. The tensions on the locking screws were higher than on the conventional ones.

Two conventional 4-hole miniplates $x$ two locking 4-hole miniplates: The tension supported by the two locking miniplates was higher than the tension supported by the two conventional miniplates, the displacement resistances of the two models were similar and the tensions on the conventional screws were a little higher than on the conventional ones.

\section{Discussion}

Osteosynthesis is one of the most discussed and investigated subjects in the literature. The bone segments must be fixated in order to attain the rigidity and stability to accelerate the healing period, and provide rapid recovery of the patient (14). If these fixation methods are not well performed they may cause serious complications to the treatment. Accordingly, the interest in investigating which is the most adequate osteosynthesis method with the lowest morbidity is increasing (12).

In order to increase the stability and improve surgical outcomes, several modifications of the fixation systems were introduced in the past years. For the fixation of bilateral sagittal split osteotomy may be used lag screws, bicortical position screws, conventional miniplates, resorbable plates, locking plate and screws and the possible combinations of them.

Clinically, the biomechanical functions of rigid fixation systems depend on the interaction between all three components, plate, screws and bone. A conventional boneplate-screws system requires precise adaptation of the plate to the underlying bone. Without this intimate contact, the tightening of the screws draws the bone segment towards the plate and results in alterations of the segment position and the occlusal relationship. In fact, the disadvantages of conventional miniplates, such as screw loosening, need of precise adaptation of the plate to the bone, stability problems and alteration in occlusion, are eliminated or decreased with the introduction of the locking plate/screw system (13-16).

The properties of locking and conventional titanium
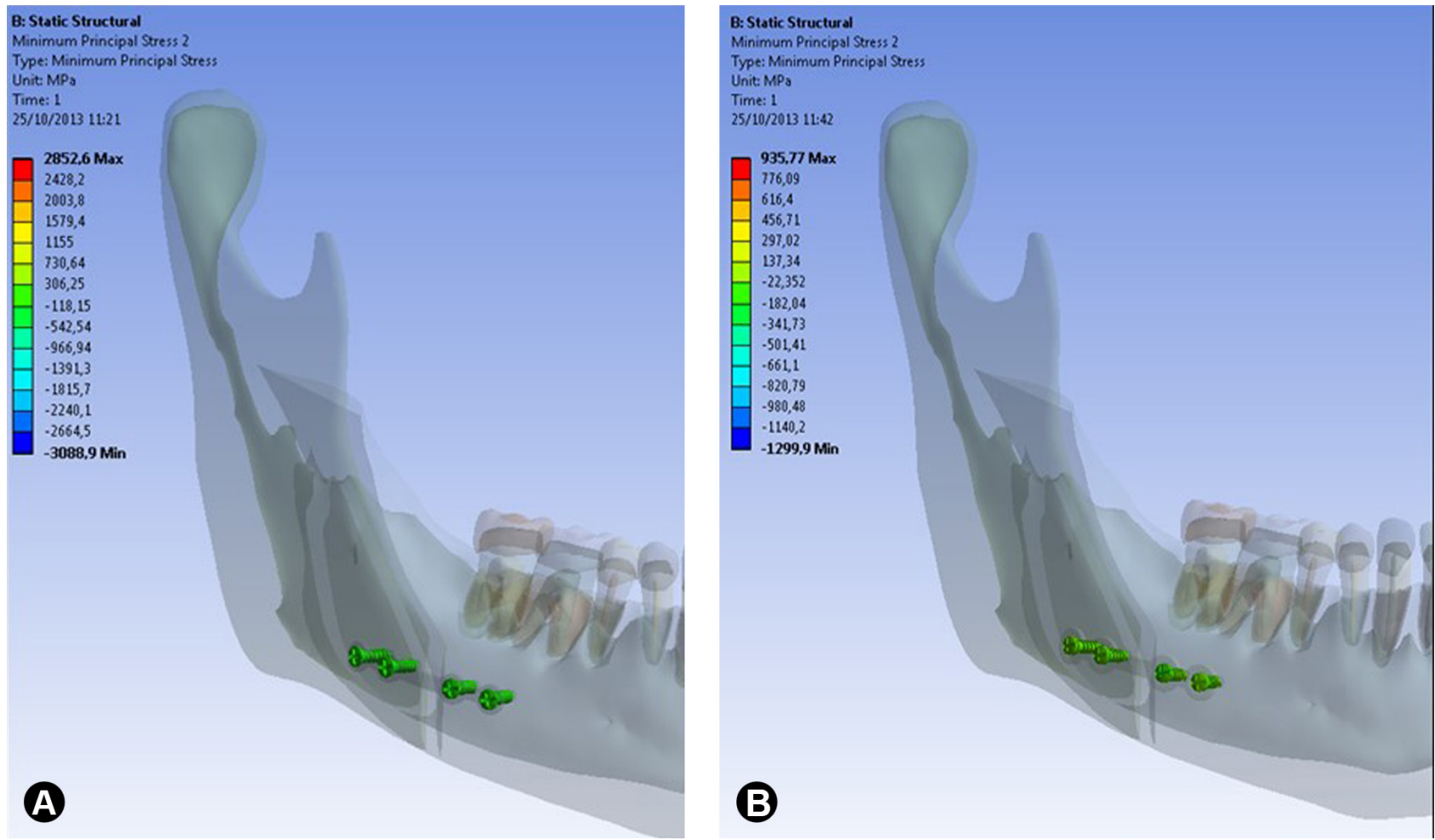

Figure 6. Images illustrating tension in the screws. A: conventional screws of the 4-hole conventional miniplate (22.352). B: locking screws of the 4-hole locking miniplate (22.532). 
systems were evaluated and it was concluded that locking plates are more stable in angle fractures $(17,18)$. The first clinical study using locking miniplate/screw was performed using the data from 80 fractures in 59 patients (13). It was found that this system was simple and provided sound fixation in all cases. However, the bond strength of 2.0- $\mathrm{mm}$ locking versus $2.0-\mathrm{mm}$ conventional mandibular miniplates was compared in a laboratory model and no differences were found between both techniques (9). It was realized that the failure relies more on the bone quality and surgical technique rather than the fixation system.

There are few studies in the literature that evaluated the stability and advantages of using locking miniplates/ screws in the fixation of bilateral sagittal split osteotomy and there are some studies that used in vitro biomechanical evaluations. An in vitro study was done to assess the biomechanical stability of 9 different osteosynthesis methods after sagittal split ramus osteotomy by simulating the masticatory forces and using a 3-point biomechanical test method. Using 45 polyurethane hemimandibles were tested 9 different fixation methods of bilateral sagittal split osteotomy using different $2.0-\mathrm{mm}$ miniplate/screws systems. A universal testing machine (Instron Co., Norwood, MA, USA) was used until a 3-mm vertical or horizontal displacement occurred between segments. These tests showed a statistically significant difference between the groups that used 2 miniplates, 1 miniplate and 1 bicortical screw and only bicortical screws, compared with groups that used only 1 miniplate with 2 screws per segment and 3 screws per segment. It was concluded that the placement of 2.0-mm diameter bicortical screws in the retromolar region, associated or not with conventional and locking miniplates with monocortical screws, provided a better stabilization of bone segments. Locking miniplates presented better performance in bone fixation in all groups. In this finite element study, addition of bicortical screws to the miniplates also increased the stability, and similar to the in vitro study, the locking miniplates seem to have better distribution of tensions and increased stability compared with the conventional system.

Stress over the bone and fixation systems after sagittal split ramus osteotomy fixed with standard titanium or locking plate/screws was also evaluated using finite element analysis in a previous study. A 3D finite element mandible model consisted of 153,320 elements, 35,570 nodes were created and $5 \mathrm{~mm}$ advancement was simulated on a computer model. The model was fixed either with $2.0-\mathrm{mm}$ titanium conventional miniplate/screw or 2.0-mm titanium locking miniplate/screw system, and a $200 \mathrm{~N}$ bite force was used. The values of von Misses stress in the cortical layer of the distal segment using the locking plate were higher. However, in the cortical layer of the proximal segment, the stress was higher in the conventional plate system. In the spongiosa layers of both segments, stress was higher in the conventional plate system. It was concluded that the locking miniplate/screw system spreads the load over the plate and screws, and diminishes the amount of force transferred to each unit.

In this study was used a more reliable 3-dimension finite element model of a mandible with 2,500,662 nodes and 1,489,170 elements, which is a high quality model compared with other studies. This model has more structures including tooth, periodontal ligament, cement, enamel and dentin. Forces similar to the forces of the masticatory muscles were used, totally different from the majority of studies related to this subject that used a single force. The association between a very realistic three-dimension model and the forces of the masticatory muscles leads to a more reliable simulation. Nine different fixation methods similar to those used in vitro by Ribeiro-Jr et al. (16) were verified. The interval of the highest and lowest values of the stress was used in the miniplate/screws and the displacement between the bone segments.

It may be observed in this study that the stress values on the miniplates were higher when locking miniplates were used, because the tension was distributed through the miniplate and less of it transferred to the bone segments. In all fixation methods, the displacement values were lower when locking miniplate/screw were used and only when two miniplates were used the values were similar. Regarding the tension verified on the screws, it may be concluded that the higher the screw tension the lower is the displacement of bone segments. It seems that the addition of bicortical screws in the fixation methods with one miniplate increases the displacement resistance of the bone segments. It seems that locking miniplate/screws provide better stabilization with less compression on the bone segments.

\section{Resumo}

0 objetivo deste estudo foi verificar o estresse e a resistência ao deslocamento, pela análise de elementos finitos, de diferentes tipos de fixação em cirurgia ortognática mandibular. Um modelo 3D de elementos finitos sólidos de uma hemi-mandíbula foi obtido. Uma osteotomia sagital bilateral foi simulada e o segmento distal foi avançado $5 \mathrm{~mm}$. Após o ajuste e sobreposição dos segmentos, foram simulados 9 diferentes tipos de osteossintese com miniplacas e parafusos 2.0: $\mathrm{A}$, uma miniplaca reta convencional de 4 furos; $B$, uma miniplaca reta lock de 4 furos; $C$, uma miniplaca convencional de 4 furos e um parafuso bicortical; $D$, uma placa lock de 4 furos e 1 parafuso bicortical; $E_{\text {, uma miniplaca reta convencional }}$ de 6 furos; F, uma miniplaca lock de 6 furos; $G$, duas miniplacas retas convencionais de 4 furos; $H$, duas miniplacas lock de 4 furos; e $I$, três parafusos bicorticais em um padrão $L$ invertido. Em cada modelo foram aplicadas forças simulando os músculos mastigatórios. Foram verificados os valores da tensão nas placas e parafusos. A resistência ao deslocamento foi verificada no segmento proximal, uma vez que o segmento distal era estável. Foi medida a região com o maior deslocamento inferior e superior. 0 deslocamento entre os segmentos osteotomizados foi verificado por intervalos milimétricos. Parafusos bicorticais em $\mathrm{L}$ invertido foram 0 
modelo que teve o menor descolamento inferior, e o modelo com a tensão mais baixa foi o de duas placas convencionais. Os resultados sugerem que a tensão foi melhor distribuida nas miniplacas do tipo lock, mas os parafusos de fixação apresentaram maior concentração de tensão.

\section{References}

1. Fernandez JR, Gallas M, Burguera M, Viano JM. A three-dimensional numerical simulation of mandible fracture reduction with screwed miniplates. J Biomech 2003;36:329-337.

2. Stoelinga PJ, Borstlap WA. The fixation of sagittal split osteotomies with miniplates: the versatility of a technique. J Oral Maxillofac Surg 2003;61:1471-1476.

3. Tyler Cox MS, Kohn MV, Impelluso T. Computerized analysis of resorbable polymer plates and screws for the rigid fixation of mandibular angle fractures. J Oral Maxillofac Surg 2003;61:481-488.

4. Van Sickels JE, Flanary CM. Stability associated with mandibular advancement treated by rigid osseous fixation. J Oral Maxillofac Surg 1985;43:338-341.

5. Erkmen E, Simşek B, Yücel $E$, Kurt A. Comparison of different fixation methods following sagittal split ramus osteotomies using threedimensional finite elements analysis Part 1: advancement surgeryposterior loading. Int J Oral Maxillofac Surg 2005;34:551-558.

6. Watzke IM, Turvey TA, Phillips C, Proffit WR. Stability of mandibular advancement after sagittal osteotomy with screw or wire fixation: a comparative study. Oral Maxillofac Surg 1990;48:108-123.

7. Peterson GP, Haug RH, Van Sickels J. A biomechanical evaluation of bilateral sagittal ramus osteotomy fixation techniques. J Oral Maxillofac Surg 2005;63:1317-1324.

8. Ribeiro-Junior PD, Magro-Filho 0, Shastri KA, Papageorge MB. In vitro biomechanical evaluation of the use of conventional and locking miniplate/screw systems for sagittal split ramus osteotomy. J Oral Maxillofac Surg 2010;68:724-730.

9. Castilho SMV, Gutiérrez S, Cañadas C, Moleon AL, López DS, Laseca EV. Contributions of the 2.0 unilock system to mandibular osteosynthesis. Rev Esp Cirug Oral Maxillofac 2004;26:287-296.
10. Sato FRL, Asprino I, Consani S, Noritomi PY, Moraes M. A comparative evaluation for the hybrid technique for fixation of the sagittal split ramus osteotomy in mandibular advancement by mechanical, photo elastic and finite element analysis. Oral Surg Oral Med Oral Pathol Oral Radiol 2012;114:S60-S68.

11. Bohluli B, Motamedi MHK, Bohluli P, Sarkarat F, Moharamnejad N, Tabrizi MHS. Biomechanical stress distribution on fixation screws used in bilateral sagittal split ramus osteotomy: assessment of 9 methods via finite element method. J Oral Maxillofac Surg 2010;68:2765-2769.

12. Ozden $B, A l k a n A$, Arici $S$, Erdem E. In vitro comparison of biomechanical characteristics of sagittal split osteotomy fixation techniques. Int J Oral Maxillofac Surg 2006;35:837-841.

13. Murphy MT, Haug RH, Barber JE. An in vitro comparison of the mechanical characteristics of three sagittal ramus osteotomy fixation techniques. J Oral Maxillofac Surg 1997;55:489-495.

14. Van Sickels JE, Peterson GP, Holms S, Haug RH. An in vitro comparison of an adjustable bone fixation system. J Oral Maxillofac Surg 2005;63:1620-1625.

15. Anucul $B$, Waite PD, Lemons JE. In vitro strength analysis of sagittal split osteotomy fixation: non-compression monocortical plates versus bicortical position screws. J Oral Maxillofac Surg 1992;50:1295-1299.

16. Choi AH, Ben-Nissan B, Conway RC. Three-dimensional modeling and finite element analysis of the human mandible during clenching. Aust Dent J 2005;50:42-48.

17. Ellis $E_{1}$ Grabam J. Use of a 2.0-mm locking plate/screw system for mandibular fracture surgery. J Oral Maxillofac Surg 2002;60:642-646.

18. Gutwald $R$, Büscher $P$, Schramm A. Biomechanical stability of an internal mini-fixation system in maxillofacial osteosynthesis. Med Biol Eng Comp 1999;37:280-290.

Received March 29, 2015 Accepted December 6, 2015 